\title{
LA NUEVA PLÁSTICA VISUAL EN TORNO AL GÉNERO, OBRA E IDENTIDAD: VALLE GALERA
}

\author{
THE NEW VISUAL PLASTIC ARTSAROUND THE GENRE, WORK AND IDENTITY:
}

VALLE GALERA

\author{
Victoria Quirosa y Laura Luque \\ Universidad de Jaén
}

\section{RESUMEN}

En este texto queremos proponer una reflexión en cuanto al propio concepto de género y cómo abordar la creación en relación a la identidad y los roles tradicionales, así como tratar aspectos relativos a las ausencias dentro del mundo del arte, ya sea en el ámbito académico, como museístico o dentro de la propia investigación y canales de difusión. Para ello, trataremos sobre la obra de la artista Valle Galera de Ulierte, una artista que trabaja en esta línea a través de la fotografía y la instalación fundamentalmente, además de mediante la investigación académica.

Palabras clave: Género, identidad, fotografía, Valle Galera.

\begin{abstract}
In this text we want to propose a reflection for the proper concept of gender and how to approach the creation in relation to the identity and the traditional roles. In addition we want to approach aspects relative to the absences inside the world of the art, whether it is in the academic area, as museums or inside research and channels of diffusion. For this reason, we will treat on the work of the artist Valle Galera de Ulierte, who is working along these, lines across the photography and the installation fundamentally, besides by means of the academic research.
\end{abstract}

Keywords: Genre, Identity, Photography, Valle Galera. 
SUMARIO

1.- Introducción: reivindicaciones pasadas y presentes. 2.- Valle Galera de Ulierte. 2.1.-Formación e inicios. 2.2.- Visibilizar identidades ignoradas. 2.3.- Últimos proyectos. 2.4.- Reivindicación de un género plural. 2.5.- Referentes. 2.6.- Técnica. 3.- Conclusiones. 4.-Bibliografía. 4.1.-Webgrafía.

\section{Introducción: reivindicaciones pasadas y presentes}

«La alternativa es inexorable: o soy viajero de las antiguas épocas, y me enfrento con un espectáculo prodigioso que me resultaría casi ininteligible o soy viajero de mi época, precipitándome en la búsqueda de una realidad desvanecida...» (Sontag, 1996:105).

Hablar del arte como catalizador del momento actual supone desprenderse de un estrecho corsé que ha marcado una conducta no escrita, por parte del espectador, que se muestra demasiado tradicional en la recepción de propuestas que van más allá de lo visual y que implican la aceptación de historias y realidades no siempre visibles en otros medios. Tal vez en este sentido las instituciones y espacios expositivos tradicionales deberían contribuir. Pero llegan con retraso, abordan de puntillas cuestiones que bajo esquemas tradicionales intentan reconciliar una deuda adquirida durante varios siglos. En esta línea el Museo del Prado, a finales de 2016, publicitaba la primera exposición monográfica dedicada a una mujer, Clara Peeters, como algo extraordinario. La propuesta en sí es positiva, pero en pleno 2017 no debería resultar extraordinario que un gran museo dedicase una exposición monográfica a una reconocida artista, puesto que resulta insuficiente.

La reivindicación de género en el arte, sin duda, puede establecerse de una forma cuantitativa; la presencia de mujeres es mínima, si bien, es un poco más visible en los espacios expositivos de arte contemporáneo. En 2012, Antonia Fernández y Marián López publicaron el libro El protagonismo de las mujeres en los museos (2012), donde se plantean las ausencias de las mujeres en los museos, no sólo de arte sino también de ciencia, una ausencia no de público, ya que son las visitantes mayoritarias, sino como creadoras. También es cierto que la mayor presencia de mujeres en los museos tradicionales debería estar precedida de una mayor investigación sobre las mujeres creadoras, en muchos casos aún desconocidas o mal estudiadas. Hay que decir al respecto que en este sentido son interesantes las aportaciones que están realizando investigadoras como Patricia Mayayo (2003) o Ángeles Caso (2016). Aun así, siguen sucediendo cosas como la que recientemente se ha vivido en Canarias. Una exposición producida por el Gobierno de la Comunidad e itinerante por las islas, recorre la historia de la pintura y la poesía canaria del siglo XX; entre los 37 artistas sólo 3 
son mujeres (del Rosario, 2017). Finalmente, la presión popular y la recogida de firmas ha hecho que el Gobierno replantee la exposición antes de aterrizar en su próximo destino.

¿Pero qué sucede cuándo se trata de arte actual? $\dot{\jmath}^{E s}$ que sigue habiendo menos artistas mujeres que hombres? Algunas artistas vienen denunciando desde hace tiempo las dificultades que encuentran para exponer, cuando en las facultades de bellas artes son mayoría. En este sentido, la artista Verónica Ruth Frías realizó una acción llamada «No», donde, partiendo de la historia de Ana Mendieta, lanzó a través de las redes sociales una propuesta para que mujeres les enviasen una fotografía propia con una barba. El proyecto se convirtió en viral a través de los medios y sobrepasó a la propia artista (Ruth Frías, 2015). Por otra parte, incluso dentro del arte urbano, algunas artistas han denunciado el machismo existente; Diana Prieto, cofundadora de Madrid Street Art Project, en una entrevista realizada en 2013 por María José Magaña (Web Arte y Cultura Visual) decía:

Es relevante el dato de que las mujeres somos minoría en el arte urbano como artistas; y sin embargo, en cuanto a personas interesadas en él, con inquietudes al respecto, somos la mayoría. Por ejemplo, el $80 \%$ de las personas que se apuntan a las actividades que organizamos desde MASP (Safaris, Talleres, etc.) son mujeres ¿̇curioso, no?

Pero en este texto queremos reflexionar sobre otras líneas de trabajo dentro del género, porque hablar sólo en clave femenina resulta reduccionista. La OMS define la palabra género no por la diferencia del sexo -característica natural o biológica-, sino como una construcción cultural que implica un conjunto de roles que se identifican como masculinos y femeninos. Actualmente se entiende que el género no está determinado únicamente por el sexo, teniendo en cuenta además la pluralidad de identidades sexuales existentes. Debe tenerse en cuenta por tanto que la identidad de género conlleva la identidad sexual, la orientación sexual y el rol de género; todo esto es importante puesto que, por ejemplo, en una pareja homosexual cada miembro puede haber adquirido un rol de género tradicional femenino/ masculino y por tanto existir evidencias de desigualdad o incluso de violencia. La igualdad de género debe encaminarse a la eliminación de los roles de género, no existiendo por tanto comportamientos que se identifiquen con lo masculino o lo femenino apropiados para cada sexo, puesto que no existe consenso en cuanto a si los roles tienen un componente biológico o son estrictamente convencionalismos sociales y culturales.

Otro de los aspectos léxicos importantes es definir bien la palabra feminismo, como el movimiento que persigue la igualdad entre sexos, dado que en nuestra sociedad actual con frecuencia se confunde el concepto y se le aplica el significado de hembrismo, que sí sería lo contrario al machismo. 
Consideramos que es el momento de que la historia del arte supere una postura que tenía sentido en la década de los sesenta, pero que hoy día nos muestra un discurso unívoco en el que a la mujer se le asigna también unos roles concretos, limitando -desde nuestro punto de vista- la propia difusión de lo que se consideran las reivindicaciones de género.

La maternidad (VV.AA. 2009 a), la demanda de sexualidad libre, se han traducido en un gran número de obras que prácticamente desde esa década de los sesenta reivindicaban un modelo de mujer no lastrado a la tradición. En esa línea destacan las obras de Judy Chicago, Cindy Sherman o Lucía Loren, etc. Hoy día hay sectores del público que piensa que los estudios de género sólo se aplican a esas temáticas. Por tanto, sería deseable que las diferentes partes implicadas en la difusión adecuada a todos los niveles apostaran por un modelo heterogéneo e inclusivo, más allá de la identidad femenina.

Es fundamental que se visibilice la obra de las artistas actuales que trabajan estas temáticas, desde diversos puntos de vista:

\section{- Académico}

Es un hecho que los contenidos de género tienen una consideración transversal en los actuales estudios de Grado en Historia del Arte, si bien, son pocos los docentes, según nuestra experiencia, que integran dichos contenidos de forma natural en sus materias. Sólo un número minoritario de universidades, en el ámbito andaluz únicamente dos, han incluido asignaturas específicas, «Arte y género» en Granada y «Estudios de género, feminismo e Historia del Arte» en Málaga. Es fundamental que los futuros especialistas en la materia no tengan una visión parcial de la Historia del Arte y que superen ese modelo decimonónico que aún prevalece. Pero no podemos obviar que no sólo los estudios universitarios deben integrar un conocimiento adecuado sobre género, también en otras etapas formativas, primaria, ESO y bachillerato deberían incluirlos; en esa línea queremos destacar el excelente trabajo realizado por Águeda Bañón, artista visual miembro del colectivo Girlswholikeporno, que ha realizado una unidad didáctica titulada «La identidad sexual en el arte contemporáneo: del género al transgénero»' ,en la que además de presentar a artistas muy interesantes, plantea una serie de talleres donde trabajar la apertura y el respeto así como la toma de conciencia de los roles sociales. Además, es importante incentivar la investigación sobre mujeres artistas para que puedan ocupar el lugar que les corresponde no sólo en las aulas y libros, sino en los museos. No queremos decir con esto que cuando hablamos de épocas pasadas deba haber paridad, pues claramente eran menos las mujeres que se pudieron dedicar al arte, pero sí que estén presentes en su justa proporción. Asimismo, se debe abrir el campo del género e incluir a otros artistas, como transgénero, poco visibles hasta el momento. 


\section{- Artístico}

Ya hemos hecho referencia a la presencia minoritaria de artistas en las bienales, ferias de arte y exposiciones temporales; son numerosos los casos que trascienden y que reivindican una mayor representación. Proyectos como la exposición «Tiempo de luz» (Rueda, 2016) que planteaba un inventario o cartografía de las artistas visuales contemporáneas en Andalucía, tanto desde un punto de vista geográfico como por vinculación con nuestra comunidad. O la ya mencionada Verónica Ruth Frías que ha reflexionado a través de su obra sobre las ausencias en los contextos expositivos $u$ otras artistas que abordan lo femenino desde otras perspectivas y con una interesantísima vinculación social a través de lo urbano o lo público y las redes sociales, como Mara León, que gracias a su proyecto «E730 ${ }^{2}$ ha conseguido movilizar a todo un colectivo para que el gobierno de Andalucía reduzca el tiempo de espera para la reconstrucción mamaria tras una mastectomía, de dos años a seis meses. Dicho proyecto ha transcendido las fronteras iniciales y actualmente continúa vigente a nivel nacional e incluso internacional.

\section{- Medios de difusión}

En pleno siglo XXI los medios de difusión perpetúan un modelo equivocado y homogéneo sobre la mujer; resulta muy interesante al respecto la obra de Yolanda Domínguez ${ }^{3}$ sus obras conectadas con el movimiento «arte de acción» pretenden reivindicar un modelo plural. Por ejemplo, en uno de sus últimos proyectos, Little Black Dress quiere generar en el espectador «una reflexión sobre género y conciencia social. Una mirada crítica a la representación de la mujer en la moda. Una invitación a abrazar la diversidad» ${ }^{4}$.Con frecuencia sus proyectos se relacionan con la publicidad y la imagen que perpetuando los roles de género tradicionales.

\section{- Nuevos formatos, nuevas posibilidades, el relevo de la fotografía y el videoarte}

El proceso creativo no establece diferencias técnicas: martillea de igual forma en la cabeza del artista que entiende la creación como una pulsión vital, catárquica y dolorosa. Lo que cambia con el paso del tiempo es el medio a través del cual hace esto. En la temática que analizamos la fotografía y los mass media en general van a ser aliados de un nuevo lenguaje plástico y visual. Uno de los valores más identificativos de la fotografía es su carga visual, aunque nosotras defendemos la subjetividad fotográfica que no se limita a un registro fidedigno,y que desde más de un siglo explora sus posibilidades plásticas desde la experimentación, o a la abstracción, un medio en el que muchos artistas se sienten más cómodos.

2 https://www.galeriacero.com/es/artistas/mara-leon(12-10-2017)

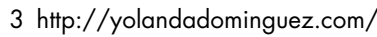

$4 \mathrm{http}$ ///yolandadominguez.com/portfolio/little-black-dress/ 


\section{Valle Galera de Ulierte 2.1. Formación e inicios}

Valle Galera de Ulierte (Jaén, 1980), siempre estuvo ligada al arte, por razones familiares. Quizá por eso a los cinco años recuerda que ya decidió que quería dedicarse a este mundo, aunque evidentemente comenzó a desarrollarse de forma profesional al mismo tiempo que avanzaba en su formación artística. Se licenció en Bellas Artes en la Universidad de Granada tras haber realizado una estancia en Tilburg (Holanda), gracias a una Beca Erasmus. Esta estancia le aportó una visión más conceptual del arte. En 2010 obtuvo el Diploma de Estudios Avanzados por la Universidad de Granada; también obtuvo el Título en el Ciclo de Artes Aplicadas y Diseño Gráfico (Fotografía Artística) en la Escuela de Artes de Granada (2008). Ha sido profesora de la Universidad de Jaén y ha trabajado como fotógrafa de prensa y revistas culturales, así como diseñadora gráfica y editora audiovisual. Además, ha realizado diferentes ilustraciones de libros como Docta Minerva o La Alhambra vivida. Recientemente se ha doctorado con un proyecto sobre fotografía e identidad. También desde el ámbito académico se ha interesado por los conflictos que supone limitar al concepto de género tradicional problemas como la violencia dentro de la pareja. El resultado es «Fotografía: masculinidades no binarias. Los excluidos y desactivadores de la violencia de género», en el que abarca el problema de la violencia de género en parejas homosexuales, no contempladas ni siquiera por la legislación entonces vigente (2012) y muy poco visibilizado en la sociedad.

En lo que se refiere a su obra artística, Valle Galera trabaja en varias disciplinas. En sus inicios se decantó por la escultura e instalación, siendo su primera exposición en este campo, con una obra que reinterpretaba la obra Las hilanderas de Velázquez y trabajaba la proporción áurea. La exposición, colectiva e itinerante, se llamó «Velázquez: una mirada actual» y tuvo lugar en 2010. Realizó en esta etapa piezas pequeñas, generalmente creando juegos de miradas y reflejos, con una gran importancia del espectador y su comportamiento. En este sentido, destaca, por ejemplo, su intervención en la plaza Grao de Castellón, en la que pasó un día contemplando y fotografiando a las mujeres que pasaban, observando cómo percibían su cuerpo y como la arquitectura y el espacio público podían influir en su comportamiento y sus movimientos. Con esta información creó un mapa sobre el terreno recogiendo los hábitos de las mujeres. Con las fotografías que había tomado realizó dibujos que convirtió en vinilos y situó en las farolas de la plaza, de forma que, de noche, cuando la mayoría de las mujeres sienten más miedo, eran ellas quienes conquistaban el espacio.

190

Dossiers Feministes, 23, 2018, 185-202 - ISSN: 1139-1219 - DOI: http://dx.doi.org/10.6035/Dossiers.2018.23.11 


\subsection{Visibilizar identidades ignoradas}

A la fotografía llegó de forma casual; fue a través de su proyecto de fin de carrera, cuando realizó una serie de fotografías de pintadas sobre lesbianismo, encontradas en las puertas de los baños de la facultad (Fig. 1). Estas fotografías fueron publicadas en forma de postales, detrás de las cuales podía leerse el lugar y la fecha en que habían sido realizadas. En algunos casos los mensajes eran contestados y nuevamente fotografiados.

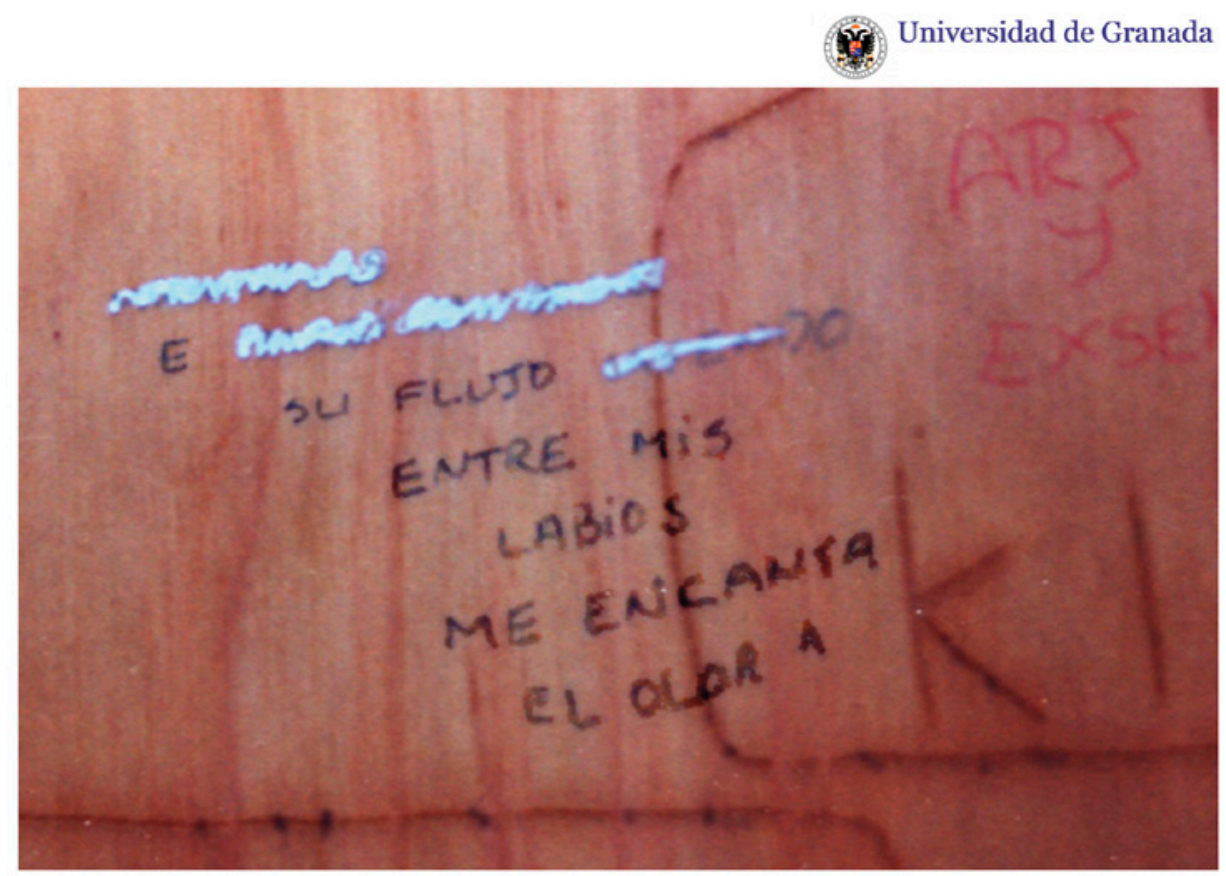

\section{SERVICIO DE SEÑORAS}

Fig. 1.

Con este proyecto inicia una de sus líneas de trabajo esenciales. Valle con su obra quiere «visibilizar identidades ignoradas, como las lésbicas del inicio o las trans, haciendo consciente al espectador que conviven con ellas pero no son conscientes, que forman parte 
de su sociedad y cultura» ${ }^{5}$. Sin embargo, una vez terminada la licenciatura, comienza a trabajar como diseñadora gráfica y editora visual, de forma que apenas tenía tiempo para la creación artística. De esta forma, la fotografía resultó ser el medio de expresión que le permitía crear. Comenzó haciendo fotografías de las cosas que sucedían en su vida, como una forma de visualizar el mundo que la rodeaba, un mundo, que le había costado encontrar y que parecía no existir. Fue creando álbumes de una familia elegida y un imaginario homosexual. De esta forma su interés por la fotografía creció y decidió formarse en este campo mientras continuaba trabajando en diseño.

En la temática de sus trabajos la artista jienense habla de personas que se buscan a sí mismas, en especial mujeres, cuestionándose constantemente qué significa en realidad ser mujer cuando se eliminan los idearios definitorios de siglos anteriores, como en el caso de su obra Crossing London (2013) en la que retrata a mujeres jóvenes que llegan solas a Londres con la ambición de poder desarrollar un deseo personal. En el entorno cotidiano de la casa, aparecen relacionadas con objetos vinculados a sus vidas. Aghate deambula por las calles con su bicicleta buscando fotos y un sentido a su vida; Rottem, gracias a que trabaja en una aerolínea israelí, puede residir en Londres y así estudiar arte, pero -al no ser europea- si deja el trabajo será deportada; Hanna desarrolla su tesis en un minúsculo y ruidoso cuarto; y Rosa es escritora para enfrentarse a su pasado. En Un día con Ariadna (2008), una joven estudiante en proceso de cambio de sexo abarca el concepto de identidad ante los demás.

La primera exposición individual de fotografía se tituló «Mujeres transexuales en el trabajo» (2008) (Figuras 2 y 3) y tuvo lugar en la sala de exposiciones de CajaSol en Sevilla.

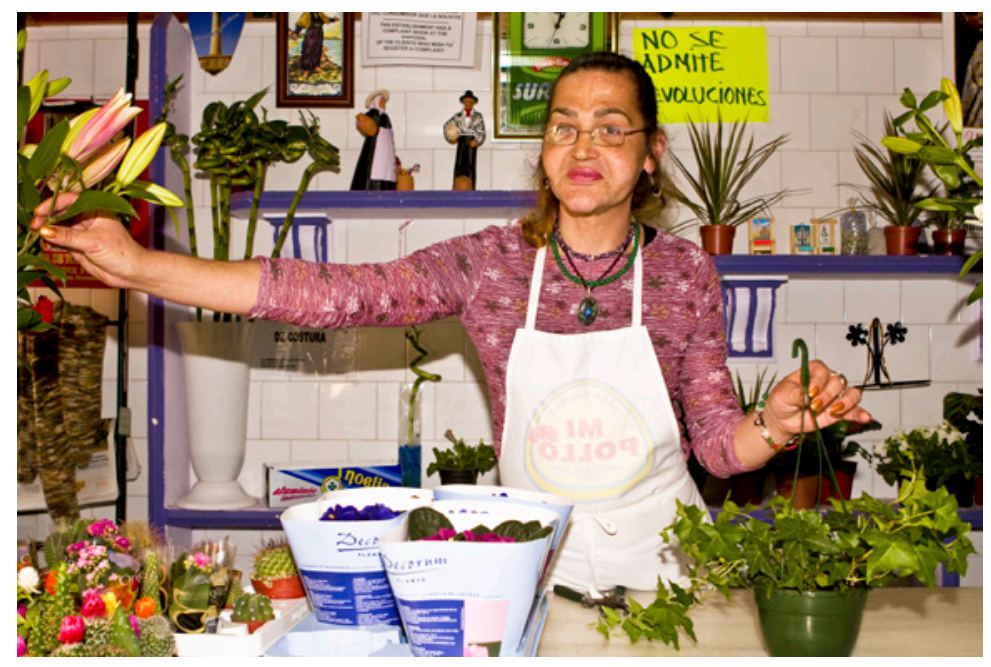

Fig. 2. 


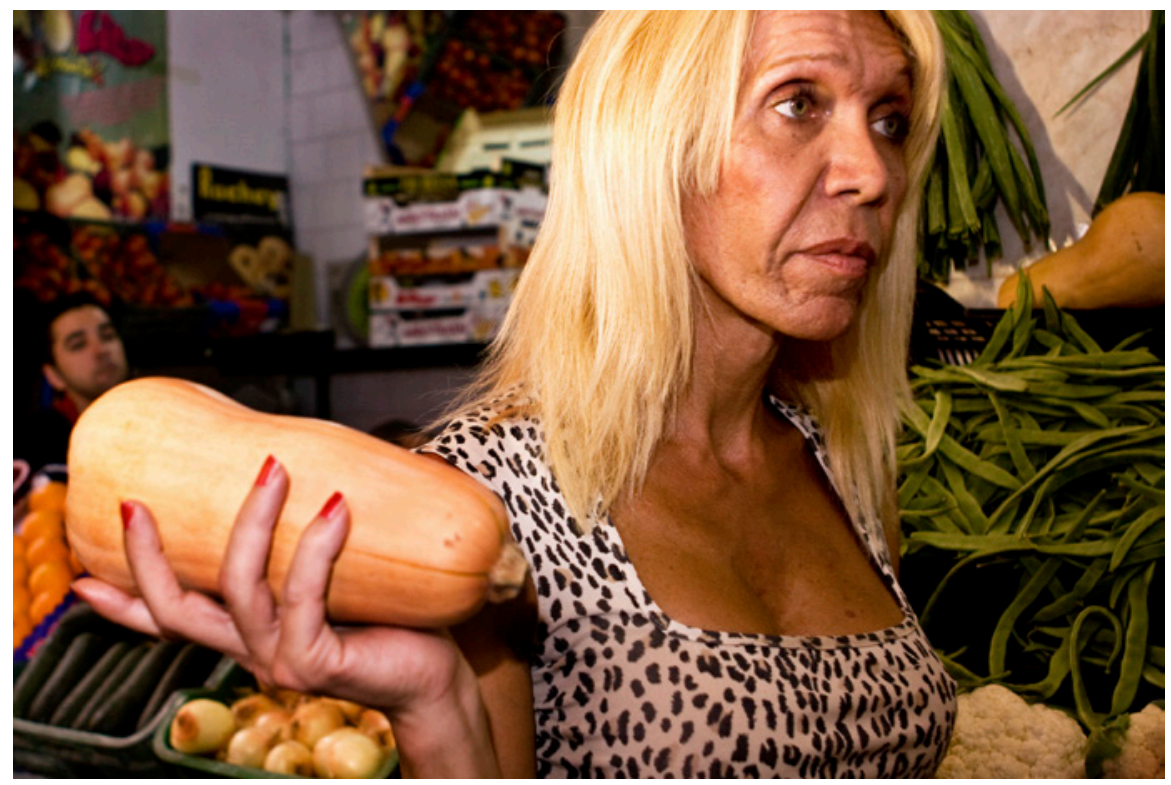

Fig. 3.

Un proyecto donde nos muestra a estas mujeres en diversos trabajos, reales o supuestos, y quehaceres cotidianos, con la intención de alejar a este colectivo del estereotipo laboral de la prostitución y mostrarlo en espacios reales y cercanos, imágenes de la vida cotidiana, transexuales desempeñando trabajos comunes como dependienta, profesora o enfermera, redefiniendo así el concepto para conseguir que deje de ser excluyente (véase la exposición de retratos para la Asociación de Transexuales de Andalucía). Valle, tiene claro en estos proyectos el alcance que desea:

Me interesa abordar tanto la orientación sexual cómo el género. El género como algo social que muta, especialmente me interesa el gesto, los gestos de la masculinidad. Investigo tanto la masculinidad en las mujeres como en los hombres. Una mujer masculina sería femenina si fuese un hombre. Esos límites tan confusos me interesan. ${ }^{6}$

En Rugby femenino busca en sus modelos actitudes como fuerza, independencia, brutalidad incluso siendo relegadas al ámbito masculino del deporte. Con un tono literario, 
secuenciado y narrativo, la autora toma prestadas vidas y situaciones ajenas para hablar de sí misma, de lo que representa el género y todas las maneras de ser mujer.

La obra de Valle Galera se articula alrededor de esos conceptos: sexo, género y rol. Cuando comenzó a trabajar la fotografía, éstas le servían para crearse referentes visuales que no existían e idear sus propias historias e historias para otros, recogiendo la realidad. Poco a poco fue descubriendo que la fotografía no es tan real, también es subjetiva y empezó a plantearse cuál era su punto de vista y qué transmitían sus imágenes. Para Valle Galera la fotografía es un certificado de existencia, algo que le ayuda a plasmar su visión personal, una ventana para descubrir. Es también un diario y una huella del paso del tiempo, como un espejo de cambios. Le sirve también como medio de relación porque empatiza con quien fotografía. Como una constante en su trabajo, Valle Galera aborda el concepto de la identidad, tanto interna como social, y la cultura callejera, a menudo suburbial o perteneciente a movimientos transexuales, otro tema recurrente en su andadura artística, alejándose en todos los casos del estereotipo y buceando en busca de la esencia global de lo inherente al ser humano.

En I LoveYou I (2014) asistimos a un barrido en rápidos fragmentos de la ciudad donde anónimos viandantes son capturados in fraganti con el móvil o la cámara Holga, generando una lectura en la que lo cotidiano se hace extraño en una segunda mirada, dotándolos de un aura de misterio que marca la distancia del asomarnos a sus existencias solo una vez y perderlos para siempre, creando una dualidad entre la presencia capturada y la ausencia manifiesta, entre el ser o no ser, lo vivido y lo imaginado.

En Reflexions (2009), Valle Galera emplea el baile y la ironía, como medio de liberación y como forma de evidenciar la falsedad de la actuación. Para ello también emplea imágenes estereotipadas, mitos del cine como una chica Bond, Olga Kurylenko, a partir del poster de la película Quantum of Solace, rasgándolo y colocándolo sobre su propio cuerpo. La obra de Valle Galera es, ante todo, una lección de sensibilidad de lo que supone ser mujer, de humanismo, por encima de todo. De respeto y de capacidad de percepción. Con sus imágenes, Valle Galera crea historias, ya sean individuales o de grupo. Le interesan las relaciones y la propia existencia. Por ello no sólo trabaja temas de género o identidad, como demuestra su reciente proyecto «Mocos, sudor y lágrimas» (2012), un mapa donde desarrollaba los vínculos en la inmigración generación tras generación.

A Valle Galera le gusta el trabajo colaborativo, sobre todo cuando le permite crear relaciones interdisciplinares. Ha trabajado, por ejemplo, con la fotógrafa Mónica Fernández, con las poetas Verónica Moreno y Olalla Castro y con la música Mercedes García en un proyecto de cinema life para el evento "Jaén en femenino»; se trató de una proyección sobre la Puerta del Ángel, compuesta de loops de películas con una narrativa no lineal, donde se podía

194

Dossiers Feministes, 23, 2018, 185-202 - ISSN: 1139-1219 - DOI: http://dx.doi.org/10.6035/Dossiers.2018.23.11 
contemplar la evolución de la imagen de mujer en el cine a través del teléfono. Por otro lado, aunque no pertenece a ningún grupo artístico, ha colaborado con LitiumLab, grupo de experimentación e investigación de nuevas tecnologías aplicadas a las artes plásticas y escénicas. La artista destaca también en su faceta de videoartista, con obras como E-mail en el servicio de señoras, o la obra stop-motion creada a partir de las imágenes de su proyecto de fin de carrera, que apareció en varios medios como el programa Metrópolis de La 2, en enero de 2005.

\section{3. Últimos proyectos}

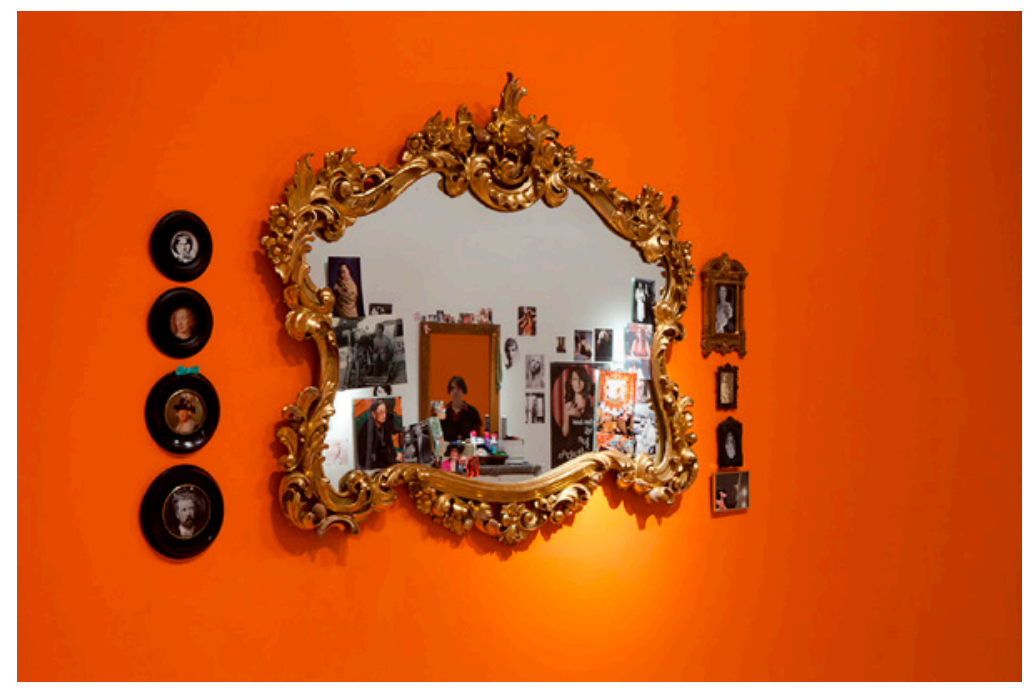

Fig. 4.

Entre sus últimos proyectos se encuentra la exposición «Dentro del espejo», que tuvo lugar en la Sala Ático de Condes de Gabia (Granada) entre el 20 de noviembre y el 15 de enero de 2014 (Figura 4). En esta exposición presentó una instalación donde recreaba dos fotografías de transexuales en un espacio privado. En ambos casos aparece un espejo rodeado de imágenes que les sirven de referentes para convertirse en las mujeres que quieren ser; al fin y al cabo, como cualquier otro ser que se «inventa» antes de salir a la calle. Se trata de dos ejemplos muy distintos: un caso es el de una señora cuyo referente podría ser la propia Reina de Inglaterra, mientras que la otra es una estudiante joven cuyo referente sería cualquier modelo actual. En palabras de la artista: 
En «Dentro del Espejo» los espectadores no eran conscientes de que las imágenes que le rodeaban eran de mujeres trans, imágenes de mujeres con las que se identificaban o deseaban, y al descubrirlo, a veces tras conversaciones tras la visita, la exposición cambia su percepción y se dan cuenta de que la mujer trans se convierte en un referente para ellos? ${ }^{7}$.

Otro de sus proyectos es «Viaje de ida y vuelta», que desarrolló junto con la poeta Olalla Castro y tuvo lugar dentro del Encuentro Memoria Joven que se celebró el 27 de noviembre de 2015 en la Sala Isidro Maiquez de la Caja de Granada (Granada).

En «Estaba oculto», expuesto en Photo España Off con la galería Twin Gallery (2015) y posteriormente en Arte Santander (2016), retrata con poses sensuales a hombres sexagenarios y homosexuales que vivieron la España del franquismo, de forma que «rescata un imaginario del seductor español que ha ido cambiando con el tiempo» ${ }^{8}$ (Figura 5).Las fotos se acompañan de refranes, argot o códigos de reconocimiento de la época. La instalación se muestra un video donde un hombre relata su primera experiencia sexual en los años 60 . Este proyecto artístico se complementa con otro de tipo académico que ha dado lugar al texto «Un espacio propio: investigación artística sobre los encuentros homosexuales en época franquista» ${ }^{9}$. Este proyecto da buena cuenta de la amplitud de la idea de género con la que trabaja Valle Galera.

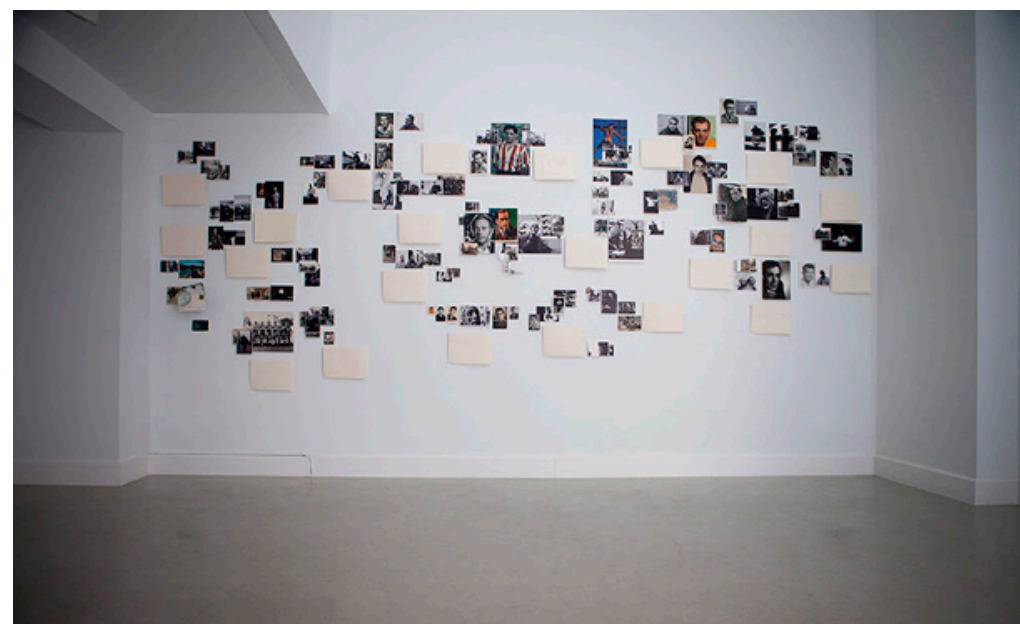

Fig. 5.

7 Entrevista por correo electrónico a Valle Galera el 11 de octubre de 2017.

$8 \mathrm{http}: / /$ twingallery.es/project/valle-galera (21/11/2017)

9 http://twingallery.es/project/valle-galera(13/10/2017) 


\subsection{Reivindicación de un género plural}

En su obra, Valle Galera reflexiona sobre nociones como la masculinidad y la feminidad, y las contradicciones en las personas, buscando hacer de lo cotidiano lo extraño y de lo diferente lo cotidiano. Su mirada es curiosa, cercana, directa y siempre respetuosa. La artista trata temas como la identidad del individuo, las zonas confusas y los límites entre categorías. Especialmente le interesa la idea que existe de mujer y las cuestiones relacionadas con esta idea como la influencia de los mass media en ella.

Para Valle Galera, el género no es algo tan simple como definirse a través de dos opciones y maneja un amplio abanico de supuestos que dotan al género de una verdadera dimensión de la personalidad de aquel a quien se alude. Para la definición de género recurre a referentes clásicos como Joan Rivière, Simone de Beauvoir o John Money, básicos en la construcción del ideario feminista y empleados por artistas en investigadoras que se adentran en el campo de los estudios de género. Así mismo, recurre a otros textos más actuales como Virginia Maqueira, Judit Butler o Beatriz Preciado, demostrando la falta de consenso existente entre filósofos, médicos y políticos, que da como resultado una concepción amplia y, en ocasiones, imprecisa (Galera, 2012) del propio concepto. Esta idea de que el concepto de género es inexacto, le sirve para reconstruirlo de una forma amplia que va más allá de la concepción binaria hombre/mujer, de manera que en su obra se reflejan otros colectivos, como transgénero, homosexualidad, lesbianismo, etc.

Su trabajo, se nutre de lo cotidiano, pero dotándolo de una segunda dimensión, su propia forma de mirar. Su obra, por tanto, es un asiento en primera fila para presenciar el mundo desde la propia cabeza de la autora. Es el mundo, sí, pero con una atmósfera distinta que nace de aislar y poner de manifiesto lo que, de otro modo, miraríamos de pasada. Desde la fotografía, busca incesantemente instantáneas que hablan de personas, de todo tipo de personas, de todo tipo de vidas y formas de expresión que transciendan los roles de género convencionales, arcaicos y no definitorios. Para Valle Galera, la fotografía es un medio de captar un momento, de congelar el gesto y la acción.

A Valle Galera le interesa mostrar a través de sus fotografías los conflictos de géneros de una forma personal e introspectiva, empleando para ello objetos como el espejo o reflejos. De esta forma la artista representa cómo actualmente a través de los reflejos cotidianos somos conscientes del yo y podemos modificar nuestra propia apariencia para adaptarla a los referentes culturales, así la imagen y los gestos que expresamos son controlados. Estas teorías encajan con los discursos de Beatriz Preciado, quien indica cómo el cuerpo está sujeto a cuestiones sociales, políticas y religiosas que lo convierten en: 
Un archivo político de lenguajes y técnicas [...], un lugar en el que se producen conflictos somatopolíticos intensísimos, lo que hace que sea prácticamente imposible que pueda existir un cuerpo plenamente sano y feliz, un cuerpo que realmente funcione como un todo homogéneo $y$ sin fisuras (Beatriz Preciado, 2011 en Web UNIA).

\subsection{Referentes}

La obra de Valle Galera visibiliza nuevos referentes que modifican el modelo social, de forma que propone una estructura de género que se enfrenta a la tradición estética y a las ideas preconcebidas: «La mirada del espectador no es inocua, viene cargada de ideología patriarcal que se enfrenta a ellos antes de mostrarse» (Galera, 2012:91). Su trabajo entronca con artistas como Diane Arbus, que apostó por el protagonismo inusitado de lo considerado hasta el momento como «lo marginal» por la sociedad de su tiempo, equiparando en sus fotografías a transexuales, prostitutas y rara avis de periferia. Sus fotografías plantearon una nueva forma de ver la realidad sin exclusiones, pero, tras este primer paso, las necesidades son otras. El arte es una herramienta de comunicación total, de provocación y los medios que se emplean en fotografía nos acercan de forma fortuita a un cambio estético y discursivo. Valle Galera tiene como referentes a artistas como Herselvis que trabaja la resistencia a aceptar la masculinidad como performance; Claude Cahun, que trata de despojar de artilugios embellecedores los cuerpos en busca de la verdad; o Cass Bird, entre otros, que retrata un mundo de mujeres masculinas, puesto que la masculinidad está ligada a valores positivos. Con todas estas referencias teóricas y estéticas, la artista construye sus obras donde, sin dejar de lado la rigurosidad técnica y sin dejar de buscar la belleza estética de las imágenes, reflexiona sobre temas tan fundamentales en la sociedad del siglo XXI como es la libertad de los cuerpos, el desmantelamiento de los roles femeninos y masculinos y la pretendida naturalidad de los seres, desarmados de atrezzo e imposiciones sociales. También entre sus maestros se encuentran otros artistas dedicados a otras disciplinas artísticas, incluso del mundo del espectáculo, como la actriz Antonia San Juan, y reconoce que son muchos sus referentes anónimos. Pero cuando hablamos de referentes no nos referimos a influencias directas y visibles en sus obras, como si analizásemos una pintura del siglo XVII que se basa en una estampa. Se trata de referentes vitales, personas, artistas o no, que han influido en su concepción del mundo, de la vida y del arte.

La artista utiliza desde la imagen fija a la imagen en movimiento (videoarte), aunque también dentro de la fotografía aparece el movimiento, sobre todo en cuanto a la representación del baile. La danza ha sido empleada como recursos para enfrentarse a lo establecido por otros artistas que son también referencias ineludibles para Valle Galera, como Pipilotti Rist o 
Gillian Wearing. De la primera, sí podemos observar la influencia más directa en sus obras, a través del movimiento del cuerpo, por ejemplo, en I'm Not The Girl Who Misses Much (1986) que podríamos compararla con la obra de Valle titulada Rasgar (2010) o en Reflexions (2009), en Rist aparece el interés por el cuerpo humano, pero si hay algo que quizá sea especialmente notable, es como tanto en la obra de Galera como en la de Rist, no tratan de ser reivindicativas a través del dolor, sino que sus creaciones tienen cierta alegría. De Wearing toma el interés por la vida cotidiana, como se refleja en la obra de Valle, Mujeres Transexuales en el trabajo (2008) o Do youlove me? (2013), entre otras, en la que explora, como Wearing, la intimidad de los espacios privados y la identidad del individuo. No obstante, la forma de acercarse al individuo fotografiado es muy distinta, resultando la de menos artificiosa.

\subsection{Técnica}

Por lo que respecta a la técnica, Valle Galera emplea generalmente una Canon 400D, una 5D Markll y una cámara Holga, entre otras, aunque cualquier medio, ya sea una lomográfica instantánea o el propio teléfono le sirve, dado que le permite fotografiar cualquier momento que no haya sido buscado. Los retoques posteriores son mínimos, apenas como corrección de contraste y enfoque. Revela en diferentes formatos, desde el papel Hahnemühle baritado o papel de algodón a soportes de aluminio laminado. En ocasiones, también emplea una especie de collage, como en Do youlove me?, donde reproduce una fotografía en un pañuelo sobre el que proyecta otra secuencia de imágenes mientras suena una canción distorsionada y una voz grita do youlove me?

\section{Conclusiones}

Con este texto queremos poner de manifiesto la necesidad de actualizar y explorar una nueva versión del género que no se circunscriba estrictamente a lo femenino, lo que nos lleva a reflexionar sobre una nueva redefinición de los estudios de género, una adecuada para el momento en el que vivimos.

Por eso en estas líneas no queremos plantear unas conclusiones al uso sino incidir sobre algunas cuestiones que se han desarrollado en el texto y que consideramos esenciales para entender las líneas que se exploran a través del trabajo de algunas artistas en la actualidad. El arte como acto comunicativo trasciende y visibiliza la pulsión vital del momento; en algunas ocasiones se anticipa o simplemente trata verdades incómodas para una porción de la sociedad, da voz y protagonismo, es un aliado esencial para mostrar los cambios. 
Nos hemos centrado en la obra de Valle Galera de Ulierte, sus proyectos apuestan de forma brillante por la visibilización de un género plural y actualizado y da protagonismo a identidades ignoradas. Su obra trasciende, reflexiona y muestra verdades incómodas para una sociedad que sigue anclada en una dualidad impuesta, femenina y masculina, viviendo de espaldas a la realidad. Afortunadamente cada vez son más los artistas que apuestan por temáticas minoritarias. Es, sin duda, un primer paso que debe complementarse con instrumentos que se implementen a nivel educativo: sólo así podrá operarse un cambio en las generaciones futuras.

\section{Bibliografía}

CASO, Ángeles (2016). Ellas mismas: autorretratos de pintoras: desde la Prehistoria hasta las Vanguardias, Madrid: Libros de la letra azul.

Fernández Valencia, Antonia y López Fernández-CaO, Marián. (2012). El protagonismo de las mujeres en los museos, Madrid: Fundamentos.

Galera, Valle (2010). Reflejos: 24 de noviembre de 2010 al 9 de enero de 2011 , sala de exposiciones Centro, Jaén, Jaén: Universidad de Jaén, Secretariado de Actividades Culturales.

GalerA, Valle (2012). «Fotografía: masculinidades no binarias. Los excluidos y desactivadores de la violencia de género». En Arte y políticas de identidad, vol. 6 (junio 2012). pp. 75-98.

http://www.m-arteyculturavisual.com/2013/06/05/binomio-arte-urbano-y-mujer/ [12/10/2017]

Mayayo, Patricia (2003). Historia de mujeres, historias del arte, Madrid: Cátedra.

Perales Acedo, Raúl (Cood.) (2009). Certamen Andaluz de fotografía 2009, Sevilla: Instituto Andaluz de la Juventud, pp. 44 - 46.

RUth FríAs, Verónica (2015). «"NO", el grito peludo de Verónica Ruth Frías por la visibilidad de la mujer», $A B C[27-05-2015]$, s.p.

http://www.abc.es/cultura/cultural/20150527/abci-proyecto-cultural-veronicaruth-201505271138.html (12/10/2017)

ORDóÑEZ, Antonio (2009). «Artistas jienenses con proyección». Ideal, 22 de enero de 2009, p. 50.

_ (2013). «Transexuales: Derecho al trabajo, derecho a una identidad». La Tribuna de Toledo, 12 de noviembre de 2013.

RuedA, Juan Francisco (2016). «Cartografía femenina». Diario Sur, 27 de agosto de 2016. http://www.diariosur.es/opinion/201608/27/cartografia-femenina20160827010625-v.html 
SONTAG, Susan (1996). Contra la interpretación, Madrid: Alfaguara.

VIRIBAY, Miguel (2009). «Creadores de Jaén reunidos en una colección». Diario Jaén, 11 de febrero de 2009, p. 35.

VV.AA. (2003). V Edición 'Arte de mujeres'. Málaga: Instituto Andaluz de la Mujer, 2003, s.p.

VV.AA. (2009 a). Mater. Universidad de Jaén.http://www10.ujaen.es/conocenos/organosgobierno/secacult/mater.

V.AA. (2009 b). Artistas jiennenses en la Colección de Arte Contemporáneo de la Universidad de Granada: Salas Provinciales de Exposición, 21 de enero al 22 de febrero de 2009, Jaén: Diputación Provincial de Jaén.

VV.AA. (2010). Configuración y discursividad en el arte actual: Reflejos, Jaén: Universidad de Jaén.

\subsection{Webgrafía}

SECCIÓN DE WEB: DEL ROSARIO, Luisa (2017) «¿Dónde estaban las mujeres?», Canarias 7 [09/10/2017], s.p.

https://www.canarias7.es/cultura/arte/polemica-pintura-y-poesia-las-tradicion-canaria-delsiglo-xx-una-controvertida-muestra-encargada-por-el-gobierno-XB2289550 (fecha de consulta 12/10/2017)

SECCIÓN DE WEB: http://vimeo.com/5275709 (fecha de consulta 21/08/2014)

SECCIÓN DE WEB: https://seiscolores.wordpress.com/page/7/ (fecha de consulta: 21/08/2014)

SECCIÓN DE WEB http://ayp.unia.es/index.php?option=com_content\&task=view\&id=703 (fecha de consulta21/08/2014).

SECCIÓN DE WEB: http://www.esmadrid.com/recursosdocesSiempreAtuEstiloMadridGayLesbian/1228099541_315201013813.pdf (fecha de consulta 21/08/2014)

SECCIÓNDEWEB:http://www.europapress.es/andalucia/fundacion-cajasol-0062 1/noticia -universidad-jaen-muestra-exposicion-parte-patrimonio-artistico-20160304113327. html (fecha de consulta 12/10/2017)

SECCIÓN DE WEB: http://www.arteinformado.com/agenda/f/estaba-oculto-12281 1 /fecha de consulta: 12/10/2017)

WEB COMPLETA: http://yolandadominguez.com/ (fecha de consulta: 13/10/2017)

SECCIÓN DE WEB: http://yolandadominguez.com/portfolio/little-black-dress/ (fecha de consulta: 13/10/2017) 
SECCIÓN DE WEB: https://www.galeriacero.com/es/artistas/mara-leon (fecha de consulta: $12 / 10 / 2017)$

SECCIÓN DE WEB: http://twingallery.es/project/valle-galera (fecha de consulta: $12 / 10 / 2017)$

WEB COMPLETA: vallegalera.blogspot.com (fecha de consulta: 12/10/2017)

WEB COMPLETA: www.girlswholikeporno.com (fecha de consulta 12/10/2017)

SECCIÓNDEWEB: http://ayp.unia.es/index.php?option=com_content\&task=view\&id=703 (fecha de consulta 22/11/2017)

Recibido el 14 de octubre de 2017 Aceptado el 27 de noviembre de 2017 BIBLID [1 139-1219 (2018) 23: 185-202] 